del debate, véase F. Vallespin Oña: Nuevas teorias del contrato social: $J$. Rawls, $R$. Nozick y $J$. Buchanor, Madrid, Alianza, 1985; S, Goyard-Fabre: Linterninable querelle du contrat social, Ottawa, Editions de l'Université d'Ottawa, 1983.

56. N. Bobbio: Estado, gobtemo, sociedad (trad. de L. Sánchez Garcia), Barcelona, Plaza y Janés, 1987, p. 163. Cfr. J.M. Gonzalez y F. Quesada (coords.): Teorfas de la democractia, Barcelona, Anthropos, 1988.

57. E. Díaz: Estado de Derecho y sociedad democrdica, Madrid, Taurus, 1981 ( $8^{\mathrm{a}}$ ed.), pp. 38. 39; De la maldad estatal y la soberamia popular, Madrid, Debate, 1984, pp. 56-57; A. Maestre: «Re- nexión para una ética en democracia: discurso ético y utopias, en Teorias de la democracia, cit., pp. 79-107; J. Muguerza: "Etica y comunicación. (Una discusión del pensamiento ético-político de Jürgen Habermas) , ibid., pp. 108-171; J. Muguerza et al. El fundamento de los derechos hamanos, Madrid, Debate, 1989.

58. Londres, Boston, Routledge and Kegan Panl, 1980. Cfr. M.E. Perkins: wLiberty and the Concept of Legitimacy in the "Discours sur linc. galité" ". Actes du IIIe Congrès Intemational sur le "Siecle des Lumières", Nancy, 1971 (ed. Banbury, 1972).

\title{
Obediencia al Derecho: revisión de una polémica
}

\author{
JUAN RAMÓN DE PÁRAMO \\ Universidad Complutense
}

Desde la publicación en 1979 del arlículo del profesor González Vicén sobre la obediencia al Derecho se ha suscitado una discusión sobre su contenido en la que han venido participando algunos miembros del gremio institucionalizado "Filosofia del Derecho, moral y polítican, unidos, esta vez sí, por un debate ético común (González Vicén 1979, 1985 y 1989; Atienza, 1983; Díaz, 1984, 1985 y 1988; Muguerza, 1986, 1987 y 1989; Fernández, 1987 y 1989; Cortina, 1987 y 1989; Guisán, 1988). Si bien parte de los argumentos en discusión han versado sobre los rasgos descriptivos del Derecho -el Derecho como institución social que disciplina y organiza la fuerza en una comunidad-, el problema de fondo ha consistido en analizar la vinculatoriedad jurídica, es decir, los diversos tipos de razones - si es que existenque ofrecen las normas jurídicas para justificar acciones o decisiones. En particular, si las normas jurídicas ofre- cen razones morales para justificar su obediencia; si existe una obligación moral de obedecer al Derecho. A veces este problema no se ha enunciado del mismo modo en la discusión, lo que ha producido respuestas diferentes.

González. Vicén (1979) partía en su argumentación de la crítica de una versión del positivismo legal -que, por cierto, no creo ni dominante ni relevante en la versión actual del positivismo jurídico- que sostiene que todo Derecho producido correctamente y revestido de validez formal obliga con independencia de su contenido. La vinculatoriedad jurídica significa aquí obligatoriedad del Derecho tan sólo por razón de su validez formal. A partir de la exposición crítica de esta tesis, González Vicén examinaba con detenimiento algunas respuestas históricas a tal cuestión: la teoría del derecho del más fuerte, del reconocimiento, del iusnaturalismo y de la seguridad jurídica; se ponía de manifiesto sus con- 
tradicciones internas $y$, sobre todo, se hacía hincapié en que ninguna de ellas ofrecía un verdadero fundamento ético para la obligatoriedad del Derecho. Precisamente, el límite de la obligatoriedad radicaba según González Vicén en la conciencia ética individual, resa profundísima soledad interior consigo mismo, de la que ha desaparecido toda exterioridad, toda limitación, ese constante retorno a sí mismo" (Hegel). Para González Vicén los imperativos de la conciencia ética individual poseen una vinculatoriedad absoluta, y cuando una norma jurídica los contradice, esta norma debe ser desobedecida. Como resultado de todo ello González Vicén llegaba a la siguiente conclusión: "mientras que no hay fundamento ético para la obediencia al Derecho, sí hay un fundamento ético absoluto para su desobediencia”. La tesis de González Vicén no afirma que no existan razones o fundamentos para obedecer al Derecho ${ }^{1}$ sino que esa posible justificación de la vinculatoriedad jurídica no constituye una obligación ética, pues ula obligatoriedad ética no se encuentra en las órdenes sociales, sino sólo en la autonomía de la individualidad moral, es decir, en los imperativos de la conciencia». El Derecho, según esta versión de la obligación, no puede crear obligaciones porque el propio concepto de obligación y el de un impcrativo procedente de una voluntad ajena y revestido de coacción son términos contradictorios. La obligación ética no puede basarse nunca en la heterono. mia de razones o motivos de indole práctica -razones de utilidad o de prudencia- sino sólo en los imperativos de la conciencia individual, que, lejos de relativizar la validez de sus imperativos, constituye, al contrario, el ultimo fundamento de su objetividad.

La contradicción entre la obligación moral y los imperativos que derivan de las disposiciones jurídicas se debe a la idea que tiene González Vícén del Derecho como instrumento técnico de dominación de las clases y de los grupos sociales, cuya contradicción inherente radica en que siendo expresión de intereses muy determinados de una situación de poder, el Derecho pretende una validez general extendida a toda la sociedad.

Atienza (1983) plantea dos objeciones a la tesis de González Vicén sobre la ínexistencia de obligaciones éticas respecto del Derecho. La primera se basa en la dimensión social de la moral y viene a decir lo siguiente: como la desobediencia ética al Derecho sólo tiene sentido en algunos supuestos -en los casos de conflicto entre las disposiciones jurídicas y las obligaciones morales- debe seguirse también la obligación ética de obedecer al Derecho "en los casos en que los mandatos jurídicos coincidan con los imperativos éticos de la conciencia individual». Sólo si se niega toda dimensión social a la ética - si se niega no el origen individual de la conciencia ética, sino su posible referencia a acciones sociales que sobrepasan la conciencia individual y que hacen coincidir el Derecho y la ética- puede sostenerse lógicamente la afirmación de González Vicén.

La segunda objeción planteada por Atienza se refiere a la fundamentación de los imperativos morales en la individualidad de la conciencia y no en la posibilidad de su generalización. Para garantizar la «razonabilidad» de las decisiones o de los imperativos éticos, si se quiere evitar algo semejante al imperativismo ético, la conciencia ética individual debería someterse a la prueba de su racionalidad, "por ejemplo, deberían cumplirse los requisitos de haber sido adoptados con suficiente información y libertad y ser suscepti- 
bles de universalización...» y no por su exclusiva referencia a la toma de decisiones individuales en un momento histórico único e irrepetible. Precisamente, sostiene Atienza, la prucba de la universalización deriva de una concepción kantiana de la moral, concepción que González Vicén parece asumir en principio. Además, se podría añadir, el punto de vista que sostiene la corrección absoluta de los imperativos de la conciencia individual es autocontradictorio, puesto que nos llevaría a proclamar la validez de enunciados incompatibles entre sí que provinieran de diferentes sujetos.

Tanto el argumento de la dimensión social de la moral como el de la prueba de la racionalidad fundamentada en algún tipo de universalización han sido recogidos por algunos de los partícipes en la polémica, como Díaz (1984), Fernández (1987), Cortina (1987 y 1989) y Guisán (1984). Precisamente, Elías Díaz (1984), partiendo de la distinción entre obligaciones jurídicas y éticas, sostiene la existencia de un fundamento ético tanto para la obediencia como para la desobediencia al Derecho, derivado de la discrepancia de fondo entre normas jurídicas y normas éticas. La coincidencia contingente entre Derecho y moral no tiene por qué desfundamentalizar éticamente el contenido de la conducta de que se trate; esta conexión no es conceptual, por lo que puede comprobarse empíricamente. Ahora bien, si la propuesta de González Vicén -sostiene E. Díaz- se reduce al formalismo de señalar que la obligación es siempre ética y que no puede haber ninguna conexión contingente con las normas jurídicas, se tendría que concluir que desde un punto de vista moral sólo se pueden desobedecer sus disposiciones. Pero la tesis de la separación conceptual entre Derecho y moral, se puede añadir, no debe confundirse con la posibilidad contingente de su coincidencia.

González Vicén (1985) no sólo le imputa a E. Díaz errores lógicos en su argumentación -el enunciado «si la conciencia individual puede fundamentar la desobediencia al Derecho, la misma razón hay para que fundamente éticamente su obediencian es tautológico-, sino también una concepción idealista y consensual del Derecho que no tiene en cuenta al mismo como instrumento técnico de dominación, con independencia del sistema político de que se trate. La tesis conocida de E. Díaz de la superioridad moral del sistema democrático y de la justificación moral de su obediencia en los casos de ausencia de conflicto entre las disposiciones jurídicas y las normas éticas -aunque, en algunos casos, como se verá en la crítica de E. Fernández (1987) ha exagerado esta propuestaes rechazada por González Vicén, porque ve imposible unificar criterios éticos individuales en decisiones colectivas tamadas por procedimientos mayoritarios. Asimismo, critica la prioridad de la libertad en el sistema valorativo que propone E. Díaz, así como la calificación política -desobediencia civil- de la desobediencia ética que es siempre una actitud personal.

La actitud favorable a las tesis de González Vicén proviene de Javier Muguerza (1986), quien, en primer lugar ve una falsa simetría en el enunciado anteriormente citado de E. Díaz, ya que la obediencia al Derecho presupone una vinculación de la conciencia individual con otras conciencias individuales en modo alguno presupuesta por su desobediencia. Pero la cuestión de fondo - las relaciones entre Ética y Derecho- es planteada con detenimiento al revisar Rousseau y Kant, y en especial, la filosofía moral construclivista representada por Habermas, 
Apel y Rawls. Para Muguerza el neocontractualismo tiene déficit de fundamentación, ya que si bien asegura el acuerdo intersubjetivo manifestado en la voluntad de los interesados, no garantiza su «racionalidad». Pero esto le lleva a plantearse un nuevo punto de vista que consiste en la conveniencia por preguntarse por los limites antes que por los findamentos del contrato social como razón justificativa de la obligación polílica; límites que no son otros que los límites del argumento de la "regla de las mayorias»; un límite superior constituido por la condición humana como categoria moral -no natural ni histórica-y un límite inferior constituido por la conciencia individual que es quien decide cuándo una decisión colectiva atenta contra la condición humana: sólo los individuos son capaces de actuar moralmente. $\mathrm{Y}$ esto está expresado en la segunda versión del imperativo categórico kantiano ( «obra de tal modo que tomes a la humanidad, tanto en tu persona como en la de cualquier otro, siempre como un fin al mismo tiempo y nunca meramente como un medion), imperativo distinto del más conocido de la universalidad. Pues bien, sostiene Muguerza, el imperativo de los fines, antes que fundamentar la obligación de obedecer. ninguna regla, su cometido es el de autorizar a desobedecer cualquier regla que el individuo crea en conciencia que contradice aquel principio. Por eso Muguerza lo denomina el imperativo de la disidencia. ${ }^{2}$ Un imperativo que confiere al individuo la legitimidad para desobedecer cualquier acuerdo o decisión colectiva que atente -según el dictado de la conciencia- contra la condición humana; de aquí no se deriva, pues, la justificación de la imposición de una minoría crítica sobre una mayoría en asuntos que requieran decisiones colectivas - como son las ma- terias de un gobiemo democrăticosino tan sólo la justificación de la desobediencia ética. Como bien ha recordado Muguerza, los golpes de Estado tienen que ver más con la imposición de obligaciones que con los actos de desobediencia.

Eusebio Fernández (1987) revisa críticamente algunos de los argumentos esgrimidos por los participantes en la polémica, y lo hace en el contexto de una obra general sobre la obediencia al Derecho. Su tesis principal sostiene que existe obligación de obedecer al Derecho siempre y cuando éste haya sido emitido de acuerdo con un peculiar procedimiento de toma de decisiones y tenga cierto contenido; más precisamente: el Derecho tiene autoridad legítima -que es lo mismo para E. Fernández que decir que existe el deber de obedecerlo- cuando cuenta con la autoridad moral que le otorga el ser un Derecho justo; y lo es suficientemente en cl caso de que se cumplan los dos requisitos combinados de haber sido producido democráticamente según el principio de legitimidad contractual y si respeta y garantiza los derechos fundamentales del hombre. E. Fernández, responde de manera ordenada a algunos de los argumentos que ya se han expuesto: critica el concepto de Derecho como dominación de clase, por considerarlo muy restringido y propio de un paleomarxismo superado. El Derecho, con independencia de la función de dominación, cumple otra serie de funciones sociales; critica el concepto de obligación moral defendido por González Vicén, proponiendo al mismo tiempo una distinción entre dos tipos de obligación: la obligación moral en sentido estricto o fuerte que cstaría basada en los imperativos de la conciencia individual y autónoma, y la obligación moral en sentido secundario o derivado, que sería el resultado 
de la aceptación por parte de la conciencia individual de una norma de origen heterónomo pero que desde el momento de su aceptación se convierte en norma moral. Esta distinción permite defender la idea de que existe una obligación moral de obedecer al Derecho justo derivada del imperativo moral de ser justos. A. Cortina (1989) ha criticado esta distinción, recordando la diferencia entre el origen y el fundamentc de las normas: si bien el fundamento de la obligación moral no se encuentra en el orden social -y sí el del Derecho-- los contenidos de los deberes morales tienen un origen tan social como los de los deberes jurídicos. Es decir, el origen de distintas legislaciones puede ser el mismo en cuanto al contenido, pero difieren por el fundamento de la obligación. Si el Derecho coincide en parte con algunas normas morales, no puede decirse que se obedezca al Derecho por razones morales; a pesar de su coincidencia, el sujeto que asume estas normas libremente, está obligado moralmente a cumplirlas no porque sean Derecho, sino porque forman parte de la moral. Todas las normas tienen un origen heterónomo (social); sólo aquellas en que es autónoma su apropiación formal se convierten en normas morales. Tarnbién plantea dos objeciones a E. Díaz; la primera se refiere a la posibilidad de un deber de obediencia "según sea el carácter y la jerarquía de los valores en conflicto" respecto de normas concretas con las que se puede estar en desacuerdo ético (E. Díaz, 1984, p. 80). Tiene razón en decir que no puede darse un deber moral de obediencia a normas jurídicas sobre las que, al mismo tiempo, se tiene un desacuerdo ético. Las razoncs prudenciales o de utilidad no sobrepasan las razones morales: en caso de desacuerdo ético con ellas, el deber moral será desobedecerlas. La segunda objeción se fundamenta en la distinción entre obligaciones morales y politicas. Ante el argumento de E. Díaz de considerar obligación moral la imposición de una conducta de omisión a quien pretende alzarse contra un régimen constitucional por medio de la fuerza, E. Fernández defiende las razones políticas para impedir esa conducta que no deben confundirse con las razones que generan obligaciones morales, ya que éstas sólo pueden surgir de actos libremente asumidos. ${ }^{3}$

Con respecio a la versión del imperativo de la disidencia de Muguerza considera que se trata de una interpretación parcial del imperativo kantiano de los fines, y que el mismo Kant mantuvo no sólo una opinión contraria al denominado derecho de resistencia, sino también una opinión favorable a obedecer al Derecho cuando las leyes consagran o no contradicen el imperativo de los fines - dándose, pues, el imperativo de la coincidencia. El individualismo ético sirve no sólo para fundamentar la disidencia sino para hacer posible la convivencia: no sólo para disentir sino para cooperar.

También Adela Cortina ha intervenido en la polémica, defendiendo las virtudes morales del principio ético de universalización (1987) y revisando el libro de E. Fernández (1989). Aun reconociendo con Muguerza que la ética discursiva resulta insuficiente para dar cuenta satisfactoria del fenómeno moral, sostiene que: 1) en la ética kantiana es impensable la supervivencia de cualquiera de las formulaciones del imperativo desligada de las demás, pues todas gozan de igual calidad moral y en especial el principio de universalización - Muguerza (1988) ha contestado a esta objeción sosteniendo que frente a la unión conceptual del imperativo de la universalidad y el de los fines, ambos cumplen diferentes 
funciones en la argumentación práctica, especialmente el segundo como corrector del primero; la dignidad humana, que es lo que se halla en juego en el imperativo de los fines, no necesita ser sometida a referéndum-; 2) por otro lado, Cortina sostiene que la conciencia individual de la que habla González Vicén es más existencialista (individualizadora) que kantiana (universalizadora). Muguerza (1988) tampoco ve una separación irreconciliable entre ambos tipos de ética; Sartre decía - recuerda Muguerza- que cuando alguien elige moralmente elige por toda la humanidad. Por lo demás, la universalización es un mecanismo corrector de la invasión ideológica del Derecho, pero también del carácter ideológico que puede contaminar la conciencia individual, que a juicio de González Vicén siempre permanece impoluta y libre de prejuicios. La universalización es el único procedimiento para superar el "corporativismo y feudalismo" democrático nacido de intereses individuales y grupales. La universalidad de las normas - mínimo moral- es condición de posibilidad del auténtico desarrollo de las diferencias, y por tanto, condición de posibilidad de un fundamento ético de la obediencia al Derecho.

E. Guisán (1988) ha sostenido que tanto la obediencia como la desobediencia a las normas jurídicas no sólo puede sino que debe estar basada en razones y justificaciones morales; sólo una concepción estricta y deformada de la ética puede negar una fundamentación de la obediencia al Derecho. Porque - sostiene E. Guisán- las normas jamás presentan el carácter de un imperativo categórico indiscutible $y$ apriorístico de la ética kantiana, sino que son siempre para algo y para alguien, y en última instancia, su justificación moral viene determinada por el servicio que presentan a la colectividad $\mathrm{y}$ a los individuos miembros de los diferentes colectivos. Sólo si el control y la coerción propias de las normas jurídicas aseguran una convivencia pacífica donde el logro de los fines y metas de los individuos sea posible, garantizándose al mismo tiempo el respeto de los derechos fundamentales de igualdad, libertad y disfrute de bienes materiales y culturales, el control y coerción propias del Derecho resultan deseables y moralmente justificables. Claro está que la justificación moral que ratifica la norma legal como éticamente legitima no puede depender únicamente del consenso mayoritario (moral positiva), ni tampoco de la conciencia individual de cada ciudadano, ya que estas últimas son, en la mayoría de los casos, cajas de resonancia de los diversos procesos de socialización. La conciencia crítica individual, para que funcione como criterio legitimador de las normas, tendría que superar ciertas pruebas formales - como el estadio seis de Kohlberg o el siete de Habermas-y que tuviera como contenido aquello que constituye, por ejemplo, el mínimo «Derecho natural» de Hart. Es decir, la apelación a la conciencia individual habría de estar "cualificada" para poder formar libremente planes de vida desde una perspectiva imparcial. De modo que el Derecho quedaria justificado moralmente si del ejercicio de esa conciencia critica cualificada se concluyera que coopera a la realización de las metas y los desiderata humanos - libertad, igualdad, bienestar, etc...-, y lleva a cabo esta tarea de tal modo que suponga el menor coste posible en sufrimientos.

Creo que en la breve e incompleta descripción de la polémica doméstica acerca de la obediencia al Derecho que acabo de transcribir hay un gran nú- 
mero de problemas y argumentos que merecen ser disculidos aunque, por otro lado, creo que no se plantea el problema de la vinculatoriedad juridica hasta sus últimas consecuencias. El Derecho puede contemplarse como un hecho social - una compleja organización disciplinada de la fuerza- pero también puede ser entendido como un conjunto de razones que justifican conductas y decisiones. El problema consiste ahora en determinar qué tipo de normatividad establece el Derecho. Porque si se dice que hay obligación moral de obedecer las normas jurídicas justas -es decir, las disposiciones jurídicas que coinciden contingentemente con las normas morales- se está diciendo que los ciudadanos tienen la obligación moral de cumplir ciertas conductas con independencia de que lo disponga o no el sistema jurídico. Como sc ha dicho algunas veces, cuando el Derecho es justo la obligación moral de obedecerlo coincide con las obligaciones morales que los individuos tendrian si ese Derecho fuera distinto o no existiera. El Derecho sería superfluo, porque lo que está justificado es la obligación moral de los sujetos con independencia de que esta conducta esté tutelada jurisdiccionalmente.

Lo que es realmente discutible es que las propias normas juridicas ofrezcan razones para justificar acciones. Porque una acción o una decisión no puede justificarse sobre la base de simples hechos, y las disposiciones juridicas, tanto en el momento de su emisión como en de la comprobación de su vigencia social, son hechos complejos entendidos como prácticas sociales. Tampoco por el hecho de que hayan sido dictadas por un procedimiento democrático se zanja la cuestión de su validez moral: aunque se pueda pensar en una presunción de justificabilidad moral de las decisiones democráticas, se trata de una presunción wiuris tantum», una presunción que se puede revocar en virtud del contenido de csas decisiones.

El modelo coexcitivo del Derecho que propone González Vicén debe ser rechazado porque no tiene en cuenta la complejidad y diversidad de normas $\mathrm{y}$ actitudes que tienen los distintos operadores y destinatarios jurídicos. Estipular que el Derecho es un conjunto de normas coactivas forma parte de una teoría imperativa basada en la idea de mandato soberano demasiado simple. No es lo mismo una disposición jurídica que prohíbe cierta conducta que una norma que confiere facultades a un individuo para otorgar un testamento. ${ }^{4}$ Esto lo ha explicado muy bien Hart en su crítica del modelo de Austin y creo que no es necesario volver a repetir aquí sus argumentos. Ahora bien, criticar el modelo coercitivo exige explicar la normatividad del Derecho como característica fundamental de los sistemas jurídicos que los hace diferentes de los simples ejercicios de la fuerza organizada. ¿Qué significa decir que A tiene una obligacion jurídica? ¿En qué radica la vinculatoriedad de las normas jurídicas? Si se dice que la vinculatoriedad juridica radica en la aceptación de las reglas, y esta aceptación no tiene un significado descriptivo - como mera predicción de un daño futuro en el caso de no conformidad-, o bien estoy equiparando la obligación jurídica a la vinculatoriedad moral, o bien estoy diciendo que la obligación jurídica tiene un status diferente. ¿De qué status se trata?

$A$ veces se dice que la obligación jurídica cs un conccpto autónomo, y que es posible hablar de la normatividad del Derecho y mantener la tesis de la separacion conceptual entre Derecho y moral. Esta tesis se basa en la impor- 
tancia de los enunciados internos, enunciados que usan el Derecho aplicándolo como pauta por medio de la cual se evalúa, guía o critica ol comportamiento. No es necesario hablar aquí de los enunciados internos y externos y de las diversas formulaciones que han tenido, pero hay que tenerlo en cuenta como un intento serio de explicar la normatividad del Derecho sin vincularlo conceptualmente con la mo$\mathrm{ral}^{5}$

Sea cual fuere la explicación de la vinculatoriedad jurídica, el problema de la obligación de obedecer el Derecho tal y como ha sido expuesto en nuestra polérnica interna no ha tenido en cuenta los distintos tipos de sujetos enfrentados con esta presunta obligación. No es lo mismo el tipo de razones que tiene un juez para seguir el Derecho que las que tiene un ciudadano para adecuar su conducta a una decisión judicial. Las razones que tuvo un juez para fundamentar su decisión en una disposición jurídica son distintas a las razones que tuvo el legislador al emitirla. Y esto con independencia del mérito moral que a juicio de cada sujeto tengan las nomas jurídicas en cada momento. La estructura del razonamiento es diferente en cada caso. No obstante, no se puede justificar "técnicamente" las pautas normativas que debe seguir un juez en función del papel que tiene asignado en un sistema jurídico. La presunta obligación moral de obediencia al Derecho que tiene un juez, o cualquier otro funcionario, no se puede derivar de la propia función que desempeña, sino de un razonamiento práctico basado en principios morales. Y esto hace de nuevo superfluo al Derecho, porque las razones morales se basan en principios morales cuya coincidencia contingente con principios jurídicos no añade ninguna cualidad moral a sus contenidos.
Por todo ello, no creo que pueda hablarse de una obligación moral general de obediencia al Derecho. La identidad de un sistema jurídico requiere unos tests formales y empíricos que no añaden nada a la calidad moral de las conductas, aunque puedan facilitar su cooperación y la omisión de conflictos. Explicar normativamente la vinculatoriedad jurídica desde un punto de vista autónomo separado conceptualmente de la moral es posible, pero plantea numerosos problemas. Deben distinguirse los distintos tipos de enunciados normativos y no normativos que forman parte de un sistema jurídico, así como las distintas actitudes y enunciados que se pueden tener y emitir sobre el sistema jurídico. Asimismo, se ha de aceptar la idea de que la teoría jurídica liene como finalidad ofrecer una descripción ajustada de un tipo específico de institución social. $\mathrm{Si}$, por el contrario, se mantiene que la teoría jurídica es un lipo especial de teotía moral preocupado en formular por qué $y$ bajo qué condiciones se puede justificar la coacción jurídica, es obvio que se debe rechazar la autonomía de la vinculatoriedad jurídica. Aceptar una teoría descriptiva o normativa del Derecho pone en juego distintos tipos de actitudes normativas que los individuos tienen sobre el Derecho.

Es obvio que el Derccho tiene una importante fuerza emotiva en virtud de su conexión con otros conceptos del razonamiento práctico, que no podemos alterar sin modificar nuestro propio vocabulario moral. Para poder expresar el grado de vinculatoriedad que tienen las disposiciones jurídicas, el Derecho ha tomado prestado de la moral conceptos normativos que producen cierta confusión al usarlos para describir situaciones típicas de contextos jurídicos, sobre todo si se pretende diferenciarlas de las conductas produ- 
cidas por situaciones de fuerza. Esto es posible, pero siempre teniendo en cuenta que de las normas jurídicas no se pueden derivar directamente razones morales para cumplirlas. Aunque existen razones generales pruden- ciales para obedecer al Derecho que derivan de la simple existencia de un sistema jurídico, no hay una obligación moral general, aunque se trate del Derecho producido por un sistema democrático.

\section{NOTAS}

1. El propio autor ha sostenido en un artícula posterior (1985) que el Derecho como ordenamiento de la conducta crea ya de por sí toda una serie de valores - la certeza de las relaciones humanas en la convivencia, el principio de imparcialidad, etc.- que constituyen razones de utilidad $\mathrm{y}$ de pridencia para su cumplimientu.

2. La conferencia de Muguerza que pronunció en el Instituto de Derechos humanos como "Tanner Lectures (1988) vuelve a insistir en el imperativo de la disidencia; su propósito consiste en fundamentar desde el disenso la idea de los derechos humanos desde el imperativo que prescribe o autoriza a decir no frente al Derecho injusto, por muy consensuada que pueda estar esa injus. ticia.
3. E. Diaz ha respondido a esta objeción (2, 1988) planteando sus dudas por la posicion cmotivista - a su juicio- de las obligaciones morales que mantiene E. Fernández. No estoy de acuerdo con esta respuesta, pues si bien las obligaciones morales sólo pueden surgir de actos libremente asumidos, estas creencias son sólo morales en la medida que son susceptibles de alguin tipo de motivación imparcial.

4. Además, la consideración de las normas juridicas como mandatos coactivos presupone un concepto univoco de norma juridica que no toma en cuenta su radical ambigüedad.

5. Sobre este punto se puede ver Páramo: "Punto de vista interno y normatividad del Derecho", en prensa.

\section{BIBLIOGRAFIA}

Arrenza, M: "La filosofía del Derecho de Felipe González Vicén", en El lenguaje del Derecho, Homenaje a G.R. Cartió, Buenos Aires, Abeledo Pertot, 1983,p. 43 y ss.

ConTnNa, A.: «La calidad moral del principio de la universaluzación, sistema, 77 (1987).

- "Sobre La obediencia al Derecho", de E. Fernández, Anuario de Filosofia del Derecho (1989).

DIAz, E.: De la maldad estatal y la soberanta popular, cap. II, Madrid, Debate. 1984.

-, «a justificación de la democracia*, Sistema (Madrid) 66 (1985).

-, alegitimidad y justicia: La Constitución, zona de mediacións, Doxa, 4 (1988).

Fernandez, E: La obediencia al Derecho, Madrid, Civitas, 1987.

-.., Réplica a Adela Cortinas, Anadrio de Fulosofia del Derecho (1989).

GONzAlEz VICEN, F.: «La obediencia al Derecho»,
Estudios de Filosofía del Derecho (La Laguna) (1979), La obediencia al Derccho: una anticriticas, Sistema, 65 (1985).

-.- "Obediencia y desobediencia al Derecho. Unas últimas reflexiones*, Sistema (1989).

Gutsán, E.: "Razones morales para obedecer al Derechow, Anates de la Cat. Fco. Suarez, 28 (1988).

Muguerza, Ja sa obediencia al Derecho y el imperativo de la disidencia (una intrusión en un debate) , Sistema, 70 (1986).

--, "Sobre el exceso de obediencia y otros excesos (un anticipo) , Doxa, 4 (1987).

-, "La alternativa del disenson, en El fundamen* to de los derechos humanos, Madrid, Debate, 1989.

PARAMO, I.R. DE: Comentario al libro La obediencia al Derecho, de E. Fernandez, Anuario de De* rechos Humartos, 5 (1988-1989). 